\title{
SARCASM: MOCK POLITENESS PERFORMED IN THE BIG BANG THEORY
}

\author{
Nico Harared ${ }^{1}$, Siti Nurani ${ }^{2}$ \\ Tanjung Barat Jagakarsa English Education Department \\ Universitas Indraprasta PGRI, Jakarta. Indonesia \\ nico.hrd@gmail.com ${ }^{1}$,rani_siti16@yahoo.com ${ }^{2}$
}

\begin{abstract}
Sarcasm has become an uncommon way to treat other's faces in communication. However, the study of sarcasm has not yet been investigated thoroughly in the case of such daily illocutionary acts of the conversations. One of the sarcasm phenomena is mostly seen in the comedy situation of The Big Bang Theory. This research aims at analyzing mock politeness or sarcasm in the utterances of each character. The analysis focuses on describing the use of mock politeness in pragmatics context. The data was obtained from informal speech acts' situations. The research carries out the descriptive qualitative method. The data was analyzed by using politeness strategy in examining the functions of mock politeness. The results show that sarcasm caused by the violation of pragmatic aspects in The Big Bang Theory releases in several types of utterances, they are: declarative, representative, and expressive. The function of sarcasm in this comedy situation mostly to create humors which are divided into several functions such as humor as a means of social critics, humor to satirize, and humor to mock.
\end{abstract}

Keywords: illocutionary act, politeness strategy, pragmatics sarcasm, speech act,

\begin{abstract}
ABSTRAK
Sarkasme menjadi cara yang tidak biasa dalam berkomunikasi. Namun belum ada penelitian sarkasme dalam percakapan tindak ilokusi. Salah satu fenomena sarkasme terdapat dalam serial komedi The Big Bang Theory. Penelitian ini bertujuan untuk menganalisis sarkasme yang dilakukan oleh para karakter. Data diambil dari percakapan informal dalam serial komedi. Penelitian ini dilakukan menggunakan metode deskriptif kualitatif. Data yang dianalisis dengan pendekatan pragmatik. Hasil penelitian menunjukkan sarkasme dalam serial komedi The Big Bang Theory dibagi menjadi beberapa tipe yaitu deklaratif, representatif, dan ekspresif. Fungsi sarkasme dalam serial ini adalah jelas untuk menciptakan humor seperti humor kritik sosial, humor satire dan humor untuk mengolok-olok.
\end{abstract}

Kata Kunci: sarkasme, tindak tutur, tindak ilokusi, kesopanan, pragmatik

\section{INTRODUCTION}

In every context of communication, speakers may deliver a speech in such ways. The language people use needs to be appropriate to the context of the situation being used, whether formal or in the informal situation of talk. Context of speech in every interaction has to be as speakers' consideration as they will meet the interaction that is properly communicated. The context of speech being used determines the speaker's attitude in conveying ideas or messages of communication. Speaker's 
behavior plays significant roles in shaping the way the interaction communicated with each other. This will release two folds of responses that are polite and impolite. Impoliteness is behaviour that is face-aggravating in a particular context (Bousfield, D. \& Locher, 2008). This implies that impoliteness is a kind of attitude within the language that may threaten one's face. This is in line that an impolite utterance contains the possibility of insulting and making others offensive. This impoliteness cannot be seen only in the speech act but also in other aspects, such as the attitude which is of great possibility to threaten other's faces.

Moreover, (Culpeper, 1996) divides impoliteness into two different categories: inherent impoliteness and mock politeness or banter. (Culpeper, 1996) "There are actions which attack one's face innately irrespective of the meaning of the act, which is known as inherent impolite. In addition the impolite which remains on the surface and is not intended to offend anyone is called mock impoliteness." This Culpeper's is also developed by (Brown \& Levinson, 1983) who differentiate impoliteness superstrategies and politeness super-strategies. Instead of enhancing or supporting face, impoliteness super-strategies are a means of attacking face.

Culpeper in (Ratri \& Ardi, 2019) describes five super-strategies, namely: 1) bald on record impoliteness, 2) positive impoliteness, 3) negative impoliteness, 4) sarcasm or mock politeness, and 5) withhold politeness. First, bald on record impoliteness happens when FTA is performed in a direct, clear, unambiguous and concise way in circumstances where the face is not irrelevant or minimized. In a certain respect, it is important to distinguish this strategy from Brown and Levinson's bald on record as for Brown and Levinson, this strategy is considered as a politeness strategy in fairly specific circumstances. For example, when face concerns are suspended in an emergency, when the threat to the hearer's face is very small (e.g. "Come in" or "Do sit down"), or when the speaker is much more powerful than the hearer (e.g. "Stop complaining" said by a parent to a child). In all these cases little face is at stake, and, more importantly, it is not the intention of the speaker to attack the face of the hearer.

Second, the use of tactics to harm a positive face is known as positive impolitely. Positive impolitancy. In addition, the use of tactics intended to harm the adjacent negative face refers to negative impolitely. In addition, when FTA is carried out using politics that are insincere, sarcasm or mock politicization occurs, thereby remaining surfacts. Lastly, preservation of elected political status determines the lack of political work to be expected. For instance, it may be considered deliberate impolitism not to thank anyone for a gift.

Mock politeness or sarcasm uttered in the various context of speech act that 
commonly function to show solidarity among speakers. (Yule, 2006) proposes that speech acts are acted in the form of utterance. It can be said that the speech act is a theory which analyses the role of utterance concerning the behavior of the speaker and listener in interpersonal communication. In brief when speakers are saying words, they not only produce utterance containing words and grammatical structure, but they also perform an action in those utterances.

Austin in (Yule, 2006) Describes speech acts of a kind like locutionary act, illustrative act and perlocutionary act. Language act is the fundamental concept of utterance that creates a significant language word. A speaker uses a recognizable word in the execution of a speech act consisting of a phrase, a sentence or a fragment, of the language. In the meantime it is an act of action; the speaker talks that is not only to say anything or to say something but is usually used to request something from someone else. In the voice, the speaker performs a speechless act in the use of a specific address. The statement has the force of a statement, a confirmation, a rejection, a forecast, a commitment, a request etc. that is not speaking about the word. The perlocutionary act is an act which affects the listener. The listener is also influenced by an utterance spoken by another. The impact the speaker has produced may be anticipated or unforeseen. In other words, a perlocution is the reaction of the listener to the context of the utterance and not necessarily physically or verbally.

The study of sarcasm has become an important aspect of the pragmatics field because it is always appearing in daily life. Sarcasm is identified as ironic or sarcastically which is intended to insult, mock or amuse. Sarcasm is directed to insult the hearer and give the opposite meaning in the conversation. To respond to several things with the true meaning but the meaning in contrast with the real meaning. Therefore, the present research is aimed to analyze more about the use of mock politeness related to the speech act's functions as both of the addresser and the addressee comprehend those functions thoroughly.

\section{LITERATURE REVIEW}

The analysis on the use of mock politeness or sarcasm in this research is based on the theory of impoliteness strategy as developed by (Culpeper, 1996) altogether with the correlation of the illocutionary acts on its types of utterances of speech act as affirmed by (Yule, 2006). The analysis of the use of mock politeness or sarcasm found in such stretches of speech uttered by characters describes some types of utterances, such as declarative, representative, expressive, directive, and commissive.

Many researchers have conducted sarcasm and politeness analysis in some 
particular research. Some of them are (Riloff et al., 2013), (Kantara, 2010), (Cheang \& Pell, 2008), (Sulis, Irazú Hernández Farías, Rosso, Patti, \& Ruffo, 2016), (Sulis et al., 2016), (Rakov \& Rosenberg, 2013) and (Bouazizi \& Otsuki, 2016). These researchers analyzed and investigated sarcasm and politeness analysis in such discussions, such the Sarcasm as Contrast between a Positive Sentiment and Negative Situation by, Impoliteness Strategies In _House M.D by (Kantara, 2010), The sound of sarcasm by (Cheang \& Pell, 2008), Figurative messages and affect in Twitter: Differences between irony, sarcasm and not by (Sulis et al., 2016), "Sure, I Did The Right Thing": A System for Sarcasm Detection in Speech by (Rakov \& Rosenberg, 2013) and A Pattern-Based Approach for Sarcasm Detection on Twitter by (Bouazizi \& Otsuki, 2016).

(Rakov \& Rosenberg, 2013) find out sarcasm is a complex and rich linguistic phenomenon. Their work identifies just one type of sarcasm that is common in tweets: the contrast between a positive sentiment and negative situation. For example, many sarcastic tweets include a positive sentiment, such as "love" or "enjoy", followed by an expression that describes an undesirable activity or state (e.g., "taking exams" or "being ignored"). They have developed a sarcasm recognizer to identify this type of sarcasm in tweets. They present a novel bootstrapping algorithm that automatically learns lists of positive sentiment phrases and negative situation phrases from sarcastic tweets. They show that identifying contrasting contexts using the phrases learned through bootstrapping yields improved recall for sarcasm recognition.

(Kantara, 2010) conducted the focus of the research on the tactics impolitely of the principal character in television show - House, M.D. Ton, and its responses, and the possible reasons/intentions behind impolitism, as set out in (Culpeper, 1996) and (Culpeper, Bousfield \& Wichman 2003). The figures included transcripts from Season 1, episodes 1-20 broadcast from http:/twiztv.com/scripts/house on Fox Television 2004-2005. This paper argues that following the conception of (Leech, 1993), which is the same as Culpeper's conception of sarcasm, the latter being an important characteristic of Dr. House's conversational style, he does not openly conflict with the Idea of Politeness but aims to be interesting, memorable and to align with the listener according to (Partington, 2007). He seems to be trying to maintain social peace in some way, by not harming the face of his partner but by allowing $\mathrm{him} / \mathrm{her}$ to hit the offensive point of his remark by inference. In addition, while he is approved by rights and the competent authority, in the sense of the hospital setting, in (SpencerOatey, 2000) circumstances, it is right that he elects indirectness. Regarding his motives, his use of impolitity in relation to his apprentices may be contrasted with training in the military (Culpeper, 1996) (Lakoff, 1989). Finally, Dr House responds 
to the implications of the uncompromising workplace mainly his trainees, who steadily escalated in impolitism (Anderson and Pearson 1999).

(Cheang \& Pell, 2008) Also carried out to classify potential sarcasm acoustic signals. Mother-of-law English speakers have created several simple terms that express four attitudes: sarcasm, satire, seriousness and neutrality. The reported speech was subjected to acoustic analysis after validation by a separate natives group of native speakers in English for the following characteristics: median fundamental frequency (F0), standard F0, mean amplitude, amplitude, speech rate, harmonical-tonoise ratio $(\mathrm{HNR})$ and one third spectral value of the octave were examined (to probe resonance changes). Results of the analysis showed that sarcasm was reliably marked by several prosodium signals, while one acoustic trait seemed especially robust in sarcastic utterances. The overall reduction in the normal HNR and F0 variance also consistently separated the sarcasm from sincerity. In such language environments, both the speaking rate and the F0 spectrum of sarcasms could be distinguished from seriousness and humor. The findings also indicated an important role in sarcasm and honesty in the language spoken by speakers. It was concluded that the language used by the speaker could influence sarcasm through speech by a certain pattern of prosodic indices in addition to textual indications.

(Sulis, et al., 2016) The open research problem explored how irony and sarcasm are differentiated from the figurative lingual phenomena and the function of features related to the multi-faceted affectionate knowledge conveyed in such texts was especially focused. The tweets labeled irony and sarcasm and even not were taken into consideration, which had not been extensively studied before. A distribution and correlation analysis of a number of features including a wide range of psycholinguistic and emotional features indicates that irony and sarcasm can be distinguished. The effect is a new set of emotions, systemic and psychological characteristics assessed during binary classification experiments. They commented on a previously used corpus for irony vs. sarcasm classification tests. You surpass the cutting-edge results of this data collection in terms of F measurements. All in all, our findings affirm the complexity of the challenge but add new reasons based on evidence to distinguish \#irony from sarcasm. Of course, it is not a straightforward phenomenon that arises.

(Rakov \& Rosenberg, 2013) conducted an automated sarcasm detection device report. They look at a variety of features suggesting sarcasm using a new acting speech corpus, which is annotated for cynical and sincere speech. The first collection of characteristics explores a basis of fundamental acoustic features which aid in the identification of human sarcasm. They have an efficient modeling system 
for the automatic detection of sarcasm and the application of prosody contours. This approach applies sequential modeling to the categorical pitch and strength contour representations achieved by clustering k-means. We can predict sarcasm with 81,57 percent accuracy using a classifier for Simple Logistics (LogitBoost). This finding indicates a predictive of sarcastic speech on some pitch and volume contours.

(Bouazizi \& Otsuki, 2016) suggested a new Twitter sarcasm detection tool. The approach suggested uses the various parts of the tweet. They use part-of-speech tags in order to extract patterns that define the sarcasm level of tweets. The method showed good results, but it could also have better results if a wider training set were used as it could not cover all potential sarcastic trends from the patterns derived from the current one. They also suggested an effective way to enrich our collection with more sarcastic trends using an initial training set of 6000 Tweets and the hashtag "\#sarcasm"'.

This research conducted sarcasm as the main core of this study. The object of the data is to differentiate this present research with the previous studies which relate in the utterances of each character containing mock politeness or sarcasm in the comedy situation entitled The Big Bang Theory. The analysis focuses on describing the use of mock politeness in pragmatics context.

The research aims at analyzing mock politeness utterances or sarcasm used from the Pragmatic point of view in a situation comedy series The Big Bang Theory. The data are qualitatively analyzed and defined by analyzing the connection between the impoliteness strategy and the types of pronouncement of the illocutionary actions.

\section{RESEARCH METHOD}

The data from this research consists of mock politeness or sarcasm expressions used in formal and informal discussions, specifically those which are present in each type of speech act (i.e. declarative, representative, expressive and directive). The data source is face-to-face dialogs between physicists and one friend who works as a waitress. The data was extracted from discussions conducted in the 17 three-season series of The Big Bang Theory situational comedy series.

This study starts with a discussion of the parameters of impolitely, in this case a conversation between characters with representative appropriate bodies to explain each mock political utterance, subdivided into several forms of utterance of a word, namely: declarative, representative, exp. The analysis will start with a discussion about the parameters of impoliteness. 


\section{FINDINGS AND DISCUSSION}

This research found several utterances that used mock politeness in the episode of the Big Bang Theory; here is one example of them:

Example 1:

\section{REPRESENTATIVE}

The participants in the dialogue are Sheldon (Physicist), Leonard (Physicist) and Penny (Waiter). They are discussing Leonard's deception toward Sheldon's data in the Arctic expedition. The conversation happens at Penny's Apartment when Leonard comes by to say hello to Penny after coming back for three months in the Arctic expedition.

\section{REP/DES/04:14-04:36/IF}

(1) Sheldon: Wolowitz has

informed me of your grand deception.

Do you have anything to say for yourself?

Leonard: Yes, I feel terrible about it. =

Penny : Can someone please tell me. What's going on here?

Sheldon : I was making groundbreaking strides in science, when in fact, I was being fed false data.

Penny : Is that true?

Leonard: It was the only way to make him happy. =

Sheldon : [[That seems like a bit of an overreaction.

Leonard : [[The overreaction was the plan to tie your limbs

Leonard : We kept the original data. You can still publish the actual results.

Sheldon: Yes, but the actual results are unsuccessful (.) and I've already sent an e-mail to everyone at the university explaining that I have confirmed string theory and forever changed man's understanding of the universe.

Leonard : [[Aw, see, yeah, you probably shouldn't have done that. So write another e-mail. Set the record straight. No big deal ((Pause))

Sheldon : ((pause)) $\underline{\text { You're }}$ 
right, Leonard. It's not a big deal. All you did was lie to me, destroy my dream and humiliate me in front of the whole university. ((Sheldon Convinced To Leonard))

That, FYI, was sarcasm. I, in fact, believe it is a big deal.

Dialogue (1) is called mock politeness to mock Leonard's utterances about his grand deception about lying to Sheldon. The statement was said by Sheldon since he realized when Leonard said that his grand deception was not a big deal.

The mock politeness above is classified as a speech act function into a representative. Here, the sentence "You're right, Leonard. It's not a big deal. All you did was lie to me, destroy my dream and humiliate me in front of the whole university." is identified as a speech act function as describing and that can be seen in his utterance such as destroy and humiliate.

The mock politeness in the conversation was categorized as humour to mock Leonard's utterances about what his grand deception in the expedition was not a big deal. It is a big deal for Sheldon which caused him to be informed of the false data. Even in the last utterances, Sheldon emphasizes that the utterance is sarcasm.

\section{DECLARATIVE}

Example 2:

The participants in the dialogue are Howard (Engineering) and Leonard (Physicist). In this episode Howard and friend have an idea to throw Leonard a kickass birthday party. Here, Howard needs to get rid of Leonard for about 2 hour.

DEC/CON/10:43-11:10/IF

(2) Howard : - Oo... oo.....

Leonard : - What's the matter?

Howard : - This granola bar has peanuts in it! ((Shout))

Leonard : - Oh, my God. Why did you eat it?

Howard : - I don't know. It was just there! ((Shout))

Leonard : If I had a gun there, would you have shot yourself?

Howard : Don't yell at me! I've got to go to the emergency room! ((Shout))

Leonard : - Now?!

Howard : - No, after my tongue has swollen to the size of a brisket! ((Shout))

Leonard : All right, just let me get my keys. 
This conversation is between Howard and Leonard in Leonard's apartment. Howard and friends are throwing Leonard a surprise party and he is supposed to keep him out of his apartments for 2 hours. The only way Howard could get him to leave was to tell him that he ate a peanut because he's allergic to peanuts. Howard asks Leonard to get him to hospital in time, but then Leonard asks Howard with rhetorical question "now?" Howard replied with sarcasm.

This kind of mock politeness is categorized as speech act function into declarative. Here, the sentence "No, after my tongue has swollen to the size of a brisket!" is identified as a speech act function as confirming. That sarcasm is classified into confirming because it can be seen in his utterance as follows "No, after my tongue has swollen to the size of a brisket!". The reaction from Leonard reveals that Leonard knows that the answer was sarcasm by saying "All right, just let me get my keys". Howard's utterance in this dialogue is called mock politeness because he wants to mock the rhetorical question from Leonard. The function of sarcasm in this conversation to create humor as humor satire.

Example 3:

DEC/CON/04:14-04:36/IF

Leonard : How do I look?

Sheldon : Could you be more specific?

Leonard : Can you tell I'm perspiring a little?

Sheldon : No. The dark crescent-shaped patterns under your arms conceal it nicely

The conversation (3) between Leonard and Sheldon was taking place in the apartment. In this section, Leonard planned to go dinner with the new beautiful female neighborhood across the hall named Penny. He asked Sheldon as his friends about his appearance for dating. Sheldon's statement is classified as sarcasm. The utterances proceeded with "No. The dark crescent-shaped patterns under your arms conceal it nicely". Then when Sheldon saw that condition, sarcasm is identified as a speech act function as confirmed from Leonard's question which can be seen in his utterance. This kind of sarcasm was conveyed by Sheldon. He means is different from the real condition but he preceded his statement with No. The function of sarcasm in this dialogue to create humor as humor satire. 


\section{EXPRESSIVE}

Example 4:

In this dialogue, the participants are Sheldon (Physicist) and Leonard (Physicist). They are talking about Leonard's lying to Penny. Leonard conveys his premise about social protocol about when you have a friend who's proud of something they suck at. Since Sheldon is aware of that premise, Sheldon gives a statement that relates to that premise to Leonard.

EXP/COM/04:14-04:36/IF

(4) Leonard : What is it?

Sheldon : I'm uncomfortable having been included in your lie to Penny.

Leonard : What was I supposed to say?

Sheldon : You could have told her the truth.

Leonard: That would have hurt her feelings.

Sheldon : (.) Is that a relevant factor? Then I suppose you could've agreed to go.

Leonard : And what would I have said afterwards?

Sheldon : I would suggest something to the effect of =

Leonard : I couldn't say that. I would have to say, "You were terrific and I can't wait to hear you sing again."

Sheldon : Why?

Leonard : That's the social protocol. It's what you do when you have a friend who's proud of something they really suck at.

Sheldon : ((pause))) I was not aware of that.

Leonard : Well, now you are.

Sheldon : All right. Leonard? When we played chess earlier, you were terrific, and I can't wait to play you again. Good night.

Conversation (4) is called mock politeness faces to mock Leonard's utterances about his social protocol about lying to Penny. Leonard cannot tell the truth to Penny because it will hurt her feelings. Afterwards, Sheldon replied with sarcasm to Leonard since he realized Leonard's social protocol about when you have a friend who's proud of something they suck at. Sheldon's utterance in this dialogue is called mock politeness because he wants to mock Leonard's statement about his social protocol premise. This kind of mock politeness is identified as speech act function into expressive for the compliment, but in fact Here, the sentence "....you were terrific and I can't wait to play you again" is identified as speech act function as complementing and that can be seen in his utterance such as terrific which is classified as complement. The function of sarcasm in this conversation is to create humor as humor social critics. 
Example 5:

EXP/DEP/02:06-00:01/IF

(5) Leonard speech in front of the students but he makes an accident after demonstrate the experimental physics because he accidentally spilt peach Snapple into a Helium neon laser and burned.

Leonard : You are considering going into experimental physics, my door is always open.

Once again, I'm sorry that the demonstration didn't quite work out, but now we know what happens when you accidentally spill Snapple into a helium neon laser. Short answer is... don't. And now to tell you about the theoretical physics department is Dr. Sheldon Cooper. ((SILENT)) Dr. Cooper?

Sheldon: $\quad$ Forget it.((from the backdoor)) Leonard: $\quad$ Excuse me. ((close to the backdoor)) Sheldon, we both agreed to do this. ((whisper))

Sheldon : It's a waste of time. I might as well explain the laws of thermodynamics to a bunch of labradoodles.

Leonard : If you don't do this, I won't take you to the comic book store.

((Sheldon appear)) Hello. ((Sheldon walked to the podium and looked at Leo's experiment))

Sheldon : $\quad$ Nice work with the laser by the way

The conversation above between Leonard (Physicist) and Sheldon (Physicist) was taking place in the class. In this section Leonard played his part to demonstrate his experimental physics in front of the students, but that demonstration didn't quite work out because he accidentally split peach Snapple into a Helium-neon laser and burned. Then when Sheldon saw that condition, sarcasm is identified as a speech act function as deploring which can be seen in his utterance as follows "Nice work with the laser by the way". This kind of sarcasm was conveyed by Sheldon in front of the students. The students here know that what Sheldon means is different from the real condition. The function of sarcasm in this dialogue to create humor as humor to mock Leonard's.

Example 6:

EXP/PRA/01:06-00:36/IF 
Leonard : We'll just bring it up ourselves.

Sheldon : I hardly think so.

Leonard : Why not?

Sheldon : Well, we don't have a dolly or lifting belts or any measurable upper-body strength.

Leonard : We don't need strengthwe're physicists.

We are the intellectual descendants of Archimedes. ((hold the box ))

Give me a fulcrum and a lever and I can move the Earth.

It's just a matter of... ((the box is fallen) $). . .$.

Sheldon : ((helped Leonard))

\section{Archimedes would be so proud.}

The conversation above between Leonard (Physicist) and Sheldon (Physicist) was taking place in the base of the apartment. Leonard insists on picking up the thing to the fifth floor since the elevator was broken, meanwhile, Sheldon refused to bring the thing upstairs by saying "I hardly think so, well, we don't have a dolly or lifting belts or any measurable upper-body strength". In this section, Leonard stated he as the descendants of Archimedes could handle the problem that he had by saying "We don't need strength- we're physicists. We are the intellectual descendants of Archimedes" but he didn't make it out and the box fell. Then Sheldon replied by saying Archimedes would be so proud". Sarcasm is identified in his utterance. Speech act function for that sarcasm as praising which can be seen in his utterance that it is fake praising or mocking. This kind of sarcasm was conveyed by Sheldon to mock Leo's statement about descendants of Archimedes. The function of sarcasm is to create humour as humour to mock Leonard's statements.

Example 7:

EXP/PRA/01:1-17:36/IF

(7) Leonard : Hi, I'm Leonard, this is Sheldon. $</ \mathrm{i}>$

We're here to pick up Penny's TV.

Intercom : Get lost.</i>

Sheldon : Okay, thanks for your time.

Leonard: We're not going to give up just like that.

Sheldon : Leonard, the TV's in the building.

We've been denied access

to the building, ergo, we are done.

Leonard : Excuse me. If I were to give up

on the first little hitch, 
I never would have identified

the fingerprints of string theory

in the aftermath of the Big Bang.(Pause)

Sheldon : My apologies. What's your plan?

Leonard : ((get close to the door and do useless thing and nothing happened))

Sheldon : It's just a privilege to watch your mind at work.

The dialogue between Leonard (Physicist) and Sheldon (Physicist) was taking place in front of the apartment Penny's boyfriend. Leonard helped Penny to pick up her TV from her ex-boyfriend. The problem is Leonard had no access to the building. Leo was trying to boast by saying "Excuse me. If I were to give up on the first little hitch, I never would have identified the fingerprints of string theory in the aftermath of the Big Bang" and he did something useless by shaking the door and nothing happened. Sheldon watched that kind of ridiculous act; he said: "It's just a privilege to watch your mind at work". The utterance is sarcasm when the word privilege contrasts with the negative situation done by Leonard. Speech act function for that sarcasm as praising it is also fake praising or mocking. This kind of sarcasm was conveyed by Sheldon also to mock Leo's statement. The function of sarcasm to create a humour as humour to mock Leonard's statements

\section{CONCLUSION}

The results show that sarcasm caused by the violation of pragmatic aspects in The Big Bang Theory has several types of utterances; they are declarative, representative, and expressive. The function of sarcasm in this series mostly to create humor which is divided into several functions such as 1) humor as a means of social criticism, 2) humor to satirize, 3) humor to disrupt reader's understanding and 4) humor to mock. For the next researchers, especially for those who intend to carry out further research in relation with the findings of this research, further studies can be applied in different approaches e.g., discourse analysis, sociolinguistics, humor and other approaches.

\section{ACKNOWLEDGEMENT}

This research was supported by Universitas Indraprasta PGRI through the Research and Community Services Institution. We are thanks to The Rector of Universitas Indraprasta PGRI, The Head of Research and Community Services Institution and The Dean of the Faculty of Humanities who have to provide us with the research funding. 


\section{BIBLIOGRAPHY}

Bouazizi, M., \& Otsuki, T. (2016). A Pattern-Based Approach for Sarcasm Detection on Twitter. IEEE Access, 4, 5477-5488. https://doi.org/10.1109/ACCESS.2016.2594194

Bousfield, D. \& Locher, M. A. (2008). Impoliteness in Language. Berlin: Mouton de Gruyter.

Cheang, H. S., \& Pell, M. D. (2008). The sound of sarcasm. Speech Communication, 50(5), 366-381. https://doi.org/10.1016/j.specom.2007.11.003

Culpeper, J. (1996). Towards an anatomy of impoliteness. Journal of Pragmatics, 25(3), 349-367.

Kantara, A. (2010). Impoliteness Strategies in "House M.D." Lodz Papers in Pragmatics, 6(2), 305-339. https://doi.org/10.2478/v10016-010-0015-9

Rakov, R., \& Rosenberg, A. (2013). " Sure, I Did The Right Thing ": A System for Sarcasm Detection in Speech Linguistics Department, The Graduate Center CUNY, New York, USA Computer Science Department, Queens College CUNY, New York , USA, (August), 842-846.

Ratri, A., \& Ardi, P. (2019). Power and impoliteness in the devil wears prada movies. Elite Journal, 6(1), 33-50. Retrieved from http://journal.uinalauddin.ac.id/index.php/elite/article/view/7923/6668

Riloff, E., Qadir, A., Surve, P., Silva, L. De, Gilbert, N., \& Huang, R. (2013). Sarcasm as Contrast between a Positive Sentiment and Negative Situation. In Emnlp (pp. 704-714).

Sulis, E., Irazú Hernández Farías, D., Rosso, P., Patti, V., \& Ruffo, G. (2016). Figurative messages and affect in Twitter: Differences between \#irony, \#sarcasm and \#not. Knowledge-Based Systems, 108, 132-143. https://doi.org/10.1016/j.knosys.2016.05.035

Yule, G. (2006). The Study of Language (third). UK: Cambridge University Press. 